\title{
Therapeutic Effects of Pembrolizumab Combined with Paclitaxel and Cisplatin Chemotherapy on Advanced Non-Squamous Non-Small Cell Lung Cancer and Influencing Factors
}

\author{
GANG WU* \\ Jiangsu Provincial Hospital of Traditional Chinese Medicine, 155 Hanzhong Road, Nanjing 210029, Jiangsu Province, China
}

Wu et al.: Treatment of Advanced Non-Squamous Non-Small Cell Lung Cancer

\begin{abstract}
To explore the therapeutic effects of pembrolizumab combined with paclitaxel and cisplatin chemotherapy on advanced non-squamous non-small cell lung cancer and its influencing factors is the main objective. A total of 87 patients with advanced non-squamous non-small cell lung cancer treated in our hospital from October 2016 to May 2018 were enrolled and allocated into control group and observation group according to their disease conditions and willingness. Paclitaxel and cisplatin chemotherapy regimen was employed for control group, based on which pembrolizumab was used for observation group. Cellular immunity indices, cytokine indices, short-term efficacy, adverse reactions, and long-term prognosis were compared, and the factors affecting short-term efficacy and long-term prognosis were analyzed. After treatment, observation group exhibited increased cluster of differentiation $3^{+} \mathrm{T}$ lymphocytes, cluster of differentiation $4^{+} \mathrm{T}$ lymphocytes, and cluster of differentiation $4^{+} /$cluster of differentiation $8^{+}$ratio and decreased cluster of differentiation $8^{+} \mathbf{T}$ lymphocytes compared with control group $(\mathbf{p}<0.05)$. After treatment, the levels of interleukin-6 and tumor necrosis factor-alpha in observation group were lower than those in control group $(\mathbf{p}<\mathbf{0 . 0 5})$. The short-term efficacy and long-term prognosis in observation group were better than those in control group $(\mathbf{p}<\mathbf{0 . 0 5})$, but statistically no significant difference in the incidence rate of adverse reactions was found between the two groups $(p>0.05)$. Decreased cluster of differentiation $4^{+} /$cluster of differentiation $8^{+}$ratio increased tumor necrosis factor-alpha level and chemotherapy were risk factors for the poor short-term efficacy and long-term prognosis in patients with advanced non-squamous non-small cell lung cancer $(p<0.05)$, and clinical stage IV was a risk factor for the unfavorable long-term prognosis as well $(\mathbf{p}<0.05)$. Pembrolizumab combined with paclitaxel and cisplatin chemotherapy regimen can relieve the cellular immune suppression and alleviate inflammatory responses to improve the short-term efficacy and long-term prognosis, without raising the incidence rate of severe adverse reactions in the treatment of advanced non-squamous non-small cell lung cancer
\end{abstract}

Key words: Pembrolizumab, paclitaxel, cisplatin, chemotherapy, non-squamous non-small cell lung cancer

Non-small cell lung cancer accounts for $85 \%$ of lung cancers, the most lethal malignancies in the world, $70 \%$ of which were non-squamous carcinomas. Non-squamous non-small cell lung cancer has been in advanced stage in the majority of patients while definitely diagnosed, so the patients miss the best timing for surgery and only receive the treatment mode dominated by radiotherapy and chemotherapy. Paclitaxel plus cisplatin is now the commonly used chemotherapy regimen in clinic, but it is less efficacious in most patients ${ }^{[1]}$. In recent years, immune checkpoint inhibitors have been gradually applied

*Address for correspondence

E-mail: wizardgun@163.com to the treatment of lung cancer, as immunotherapy continues to develop. Programmed cell death protein-1 (PD-1), mainly expressed on the surface of T cells, is an important immune checkpoint, and an anti-PD-1 monoclonal antibody binds to PD-1 to block its binding

This is an open access article distributed under the terms of the Creative Commons Attribution-NonCommercial-ShareAlike 3.0 License, which allows others to remix, tweak, and build upon the work non-commercially, as long as the author is credited and the new creations are licensed under the identical terms

Accepted 26 January 2021

Revised 05 October 2020

Received 19 June 2020

Indian J Pharm Sci 2021;83(1):120-126 
to programmed death receptor-ligand 1 (PD-L1) and PD-L2 and remove the immunosuppressive effect, thereby activating the functions of $\mathrm{T}$ cells and enabling them to find and attack tumor cells ${ }^{[2]}$. Currently, there have been few reports on the efficacy of the PD-1 inhibitor pembrolizumab combined with paclitaxel and cisplatin chemotherapy regimen in treating advanced non-squamous non-small cell lung cancer. Therefore, the present study aims to observe the efficacy of pembrolizumab combined with paclitaxel and cisplatin chemotherapy regimen in the treatment of advanced non-squamous non-small cell lung cancer and patient's adverse reactions explore the possible mechanism of action and analyze the influencing factors.

\section{MATERIALS AND METHODS}

\section{Clinical data:}

A total of 87 patients with advanced non-squamous non-small cell lung cancer, who were treated in our hospital from October 2016 to May 2018 were recruited. Inclusion criteria: Patients definitely diagnosed with non-squamous non-small cell lung cancer according to fiberoptic bronchoscopy, lung biopsy or cytology; those in the clinical stages III and IV; those with an expected survival time of over $90 \mathrm{~d}$; those who were initially diagnosed and treatment naive; those with basically normal hematopoietic system, heart, liver, and kidney functions; those who had a Karnofsky performance status score of exceeding 70 points and a physical status score of less than 2 points and could tolerate immunotherapy and chemotherapy; those with measurable or assessable lesions and those who and whose family members provided the informed consent to the present study and treatment schemes and singed for confirmation. Exclusion criteria: Patients who suffered from intolerable adverse reactions or could not complete the whole treatment or those with incomplete clinical case data. The present study was reviewed and approved by the Medical Ethics Committee of our hospital. According to the disease conditions and willingness, the patients were assigned into control group and observation group. Among the 48 patients in control group, 30 were male, and 18 were female, with an age of 38-65 y old and a mean of (50.92 \pm 5.57$)$ y old, and there were 29 cases of stage III non-squamous nonsmall cell lung cancer and 19 cases of stage IV nonsquamous non-small cell lung cancer. In observation group, the 39 patients consisted of 25 females and 14 males, aged 39-65 y old with a mean of $(51.28 \pm 5.63) \mathrm{y}$ old, and there were 23 cases of stage III non-squamous non-small cell lung cancer and 16 cases of stage IV nonsquamous non-small cell lung cancer. No statistically significant differences were found regarding general data of patients $(\mathrm{p}>0.05)$.

\section{Treatment methods:}

Paclitaxel and cisplatin chemotherapy regimen was adopted in control group as follows: On the 1st $\mathrm{d}$ of the chemotherapy, $135 \mathrm{mg} / \mathrm{m}^{2}$ paclitaxel injection (30 mg/piece, NMP No.: H20063787, Beijing Youcare Pharmaceutical Group Co., Ltd.) was diluted in 500 $\mathrm{ml}$ of sodium chloride injection and intravenously dripped for $3 \mathrm{~h}$. At $12 \mathrm{~h}$ and $6 \mathrm{~h}$ before treatment, $10 \mathrm{mg}$ of dexamethasone was orally taken, while $20 \mathrm{mg}$ of diphenhydramine was intramuscularly dripped at $0.5-1 \mathrm{~h}$ before treatment. On the $2^{\text {nd }}-$ $5^{\text {th }} \mathrm{d}$ before the chemotherapy, $20 \mathrm{mg} / \mathrm{m}^{2}$ cisplatin injection (30 mg/piece, NMP No.: H20040813, Jiangsu Hansoh Pharmaceutical Group Co. Ltd.) was first diluted in $500 \mathrm{ml}$ of sodium chloride injection and intravenously dripped. Before treatment, metoclopramide was administered, and adequate hydration therapy was required at 2-16 $\mathrm{h}$ before treatment and within at least $6 \mathrm{~h}$ after treatment. A chemotherapy cycle lasted for $3 \mathrm{w}$, and the whole treatment was performed for 4 cycles. In addition to the paclitaxel and cisplatin chemotherapy regimen, pembrolizumab (MSD, Carlow, Ireland) was diluted in sodium chloride injection at a dose of $3 \mathrm{mg} / \mathrm{kg}$ and then intravenously dripped for $60 \mathrm{~min}$ in observation group, and with $2 \mathrm{w}$, as a cycle, the treatment lasted for 6 cycles.

\section{Detection of cellular immunity indices:}

At $1 \mathrm{~d}$ before treatment and $2 \mathrm{w}$ after treatment, $2 \mathrm{ml}$ of peripheral venous blood was drawn from patients. Then the cluster of differentiation $3^{+}\left(\mathrm{CD}^{+}\right)$T lymphocytes, cluster of differentiation $4^{+}\left(\mathrm{CD}^{+}\right) \mathrm{T}$ lymphocytes and cluster of differentiation $8^{+}\left(\mathrm{CD} 8^{+}\right) \mathrm{T}$ lymphocytes were detected using a FACSCalibur flow cytometer (BD Pharmingen, United States of America (USA), and the $\mathrm{CD}^{+} / \mathrm{CD}^{+}$ratio was calculated. Finally, the data were analyzed using the CellQuest software.

\section{Detection of cytokine indices:}

At $1 \mathrm{~d}$ before treatment and $2 \mathrm{w}$ after treatment, $4 \mathrm{ml}$ of peripheral venous blood was collected from patients, and centrifuged. The supernatant was then obtained, and the levels of interleukin-6 (IL-6) and tumor necrosis factor-alpha (TNF- $\alpha$ ) were determined using enzymelinked immunosorbent assay (ELISA) and the high- 
sensitivity IL-6 ELISA kit (ab46042, Abcam, USA) and human TNF- $\alpha$ ELISA kit (ab181421, Abcam, USA).

\section{Evaluation of therapeutic effects and adverse reactions:}

At $2 \mathrm{w}$ after treatment, with reference to Response evaluation criteria in solid tumors (RECIST) 1.1, complete disappearance of measurable lesions with the short diameter of pathological lymph nodes decreased to $10 \mathrm{~mm}$ for more than $4 \mathrm{w}$ was defined as complete response (CR), a $\geq 30 \%$ decrease in the sum of the diameters of measurable lesions for more than $4 \mathrm{w}$, as partial response (PR), $a \geq 20 \%$ increase in the maximum diameter of measurable lesions or appearance of one or more new lesions as progressive disease (PD), and neither sufficient decrease in the target lesions to qualify for PR nor sufficient increase in them to qualify for PD for more than $4 \mathrm{w}$, as stable disease (SD). The disease control rate was calculated as follows: disease control rate $=\mathrm{CR}$ rate $+\mathrm{PR}$ rate $+\mathrm{SD}$ rate. The adverse reactions of the patients were observed.

\section{Re-examination and follow-up:}

Computed tomography (CT) re-examination was performed once monthly, and the patients were followed up once at least every 3 mo until the death of patients or $2 \mathrm{y}$ after treatment. The progression-free survival (PFS), overall survival (OS), 1 y OS rate, and 2 y OS rate of the patients were mainly evaluated. PFS referred to the duration from the start of treatment to recurrence, while OS meant the duration from the start of treatment to the death of patients or the deadline of follow-up.

\section{Statistical analysis:}

Data were analyzed using Statistical Package for the Social Sciences (SPSS) 16.0 software. Quantitative data were represented as $\left(\chi^{ \pm} \mathrm{s}\right)$, and they were compared between groups by independent samples $t$ test and at different time points using paired $t$ test. Numerical data were expressed as $n(\%)$ and compared with $\chi^{2}$ test.
Log-rank test (Mantel-Cox test) was performed using GraphPad Prism software to compare the survival time and survival rate, and survival curves were plotted by the Kaplan-Meier method. The test level was set as $\alpha=0.05$, and two-sided $p<0.05$ was considered to be statistically significant.

\section{RESULTS AND DISCUSSION}

Compared with those before treatment, the $\mathrm{CD}^{+} \mathrm{T}$ lymphocytes, $\mathrm{CD} 4^{+}$lymphocytes and $\mathrm{CD} 4^{+} / \mathrm{CD}^{+}$ratio rose, whereas the CD8+ T lymphocytes declined in both groups after treatment, and the intragroup differences between the two time points were statistically significant $(p<0.05)$. Before treatment, no statistically significant differences were observed between the two groups $(\mathrm{p}>0.05)$. After treatment, observation group had more $\mathrm{CD}^{+} \mathrm{T}$ lymphocytes and $\mathrm{CD} 4^{+} \mathrm{T}$ lymphocytes and a higher $\mathrm{CD}^{+} / \mathrm{CD}^{+}$ratio than control group $(\mathrm{p}<0.05)$ (Table 1).

After treatment, the levels of IL- 6 and TNF- $\alpha$ dropped in both groups compared with those before treatment $(p<0.05)$. Before treatment, there were no statistically significant differences between the two groups $(p>0.05)$, and the levels of IL- 6 and TNF- $\alpha$ in observation group were lower than those in control group after treatment $(\mathrm{p}<0.05)$ (Table 2).

There were no case of CR, 9 cases of PR, 16 cases of $\mathrm{SD}$ and 23 cases of $\mathrm{PD}$, and the disease control rate was $52.08 \%$ in control group. Observation group had 4 cases of CR, 12 cases of PR, 13 cases of SD and 10 cases of PD, with a disease control rate of $74.36 \%$. The short-term efficacy in observation group was better than that in control group $(\mathrm{p}<0.05)$ (Table 3$)$.

The incidence rate of adverse reactions in observation group and control group were $62.50 \%$ and $71.79 \%$, respectively $(\mathrm{p}>0.05)$ (Table 4$)$.

Observation group and control group had a median PFS of $5.8 \mathrm{mo}$ and $11.7 \mathrm{mo}$, a median OS of $13.5 \mathrm{mo}$ and $20.4 \mathrm{mo}, 1 \mathrm{y}$ OS rate of $31.25 \%$ and $53.85 \%$, and $2 \mathrm{y}$

TABLE 1: CELLULAR IMMUNITY INDICES ( $X \pm s)$

\begin{tabular}{lccccc}
\hline Group & Time & CD3 $^{+}(\%)$ & CD4 $^{+}(\%)$ & CD8 $^{+}(\%)$ & CD4 $^{+} /$CD8 $^{+}$ratio \\
\hline \multirow{2}{*}{ Control group $(n=48)$} & Before treatment & $57.83 \pm 5.96$ & $25.74 \pm 3.16$ & $29.45 \pm 3.37$ & $0.90 \pm 0.21$ \\
Observation group & After treatment & $60.49 \pm 6.12$ & $27.38 \pm 3.35$ & $28.02 \pm 3.24$ & $1.01 \pm 0.24$ \\
$(\mathrm{n}=39)$ & Before treatment & $57.61 \pm 5.78$ & $25.62 \pm 3.09$ & $29.73 \pm 3.32$ & $0.89 \pm 0.21$ \\
$\mathrm{t} / \mathrm{p}_{\text {in the group before treatment }}$ & After treatment & $66.72 \pm 6.85$ & $30.17 \pm 3.68$ & $22.84 \pm 2.95$ & $1.37 \pm 0.34$ \\
$\mathrm{t} / \mathrm{p}_{\text {in the group after treatment }}$ & & $0.174 / 0.863$ & $0.178 / 0.859$ & $0.388 / 0.699$ & $0.221 / 0.826$ \\
$\mathrm{t} / \mathrm{p}_{\text {in control group }}$ & & $4.476 / 0.000$ & $3.696 / 0.000$ & $7.717 / 0.000$ & $5.778 / 0.000$ \\
$\mathrm{t} / \mathrm{p}_{\text {in observation group }}$ & & $2.154 / 0.034$ & $2.467 / 0.015$ & $2.119 / 0.037$ & $2.390 / 0.019$ \\
\hline
\end{tabular}


OS rate of $10.42 \%$ and $33.33 \%$, respectively $(\mathrm{p}<0.5)$ (fig. 1).

With all the factors as independent variables, and the disease control and progression of patients as the dependent variables, the independent variables were assigned as follows: age: $\geq 50$ y old $=1$ and $<50$ y old $=0$, sex: male $=1$ and female $=2$, clinical stage: stage $I V=1$ and stage III $=0, \mathrm{CD}^{+} \mathrm{T}$ lymphocytes: $\geq 58.00 \%=1$ and $<58.00 \%=0, \mathrm{CD}^{+} \mathrm{T}$ lymphocytes: $\geq 26.00 \%=1$ and $<26.00 \%=0, \mathrm{CD}^{+} \mathrm{T}$ lymphocytes: $\geq 30.00 \%=1$ and $<30.00 \%=0, \mathrm{CD}^{+} / \mathrm{CD}^{+}$ratio: $\geq 0.90=1$ and $<0.90=0$, IL-6: $\geq 90.00 \mathrm{ng} / \mathrm{l}=1$ and $<90.00 \mathrm{ng} / \mathrm{l}=0, \mathrm{TNF}-\alpha: \geq 390.00$ $\mathrm{ng} / \mathrm{l}=1$ and $<390.00 \mathrm{ng} / \mathrm{l}=0$, nuclear factor- $\kappa \mathrm{B}(\mathrm{NF}-\kappa \mathrm{B})$ : $\geq 5.00 \mathrm{ng} / \mathrm{l}=1$ and $<5.00 \mathrm{ng} / \mathrm{l}=0$, and treatment methods: paclitaxel and cisplatin chemotherapy regimen=1 and pembrolizumab combined with paclitaxel and cisplatin chemotherapy regimen $=0$. According to the logistic multivariable regression analysis results, the decreased $\mathrm{CD}^{+} / \mathrm{CD}^{+}$ratio, increased $\mathrm{TNF}-\alpha$ level and chemotherapy were the risk factors for the disease progression in patients with advanced non-squamous non-small cell lung cancer $(\mathrm{p}<0.05)$ (Table 5).

All the factors were taken as independent variables, and the survival and death of patients were set as dependent variables. The assignment of the independent variables was the same as that in 2.6. It was found through the logistic multivariable regression analysis that the clinical stage IV, decreased $\mathrm{CD} 4^{+} / \mathrm{CD}^{+}$ratio, increased TNF- $\alpha$ level and chemotherapy were the risk factors for the death of patients with advanced non-squamous nonsmall cell lung cancer within 2 y $(\mathrm{p}<0.05)$ (Table 6).

There are unbalanced proportions of lymphocyte subpopulations in the peripheral blood in lung cancer patients, which suggests cellular immunosuppression. Therefore, immunotherapy has been extensively applied to the treatment of lung cancer in recent years ${ }^{[3]}$. When binding to its ligands PD-L1 and PDL2, PD-1, expressed on activated T lymphocytes, can repress the activation of $\mathrm{T}$ cells, further inhibiting the anti-tumor immune response, whereas anti-PD-1 monoclonal antibody is able to bind to PD-1 to relieve the immunosuppressive state of Tlymphocytes, thereby restoring their anti-tumor effect ${ }^{[4]}$. Normally, $\mathrm{CD}^{+} \mathrm{T}$ lymphocytes represent mature $\mathrm{T}$ lymphocytes in the peripheral blood, while $\mathrm{CD}^{+}$helper $\mathrm{T}$ lymphocytes can promote the proliferation and differentiation of immune cells and coordinate the interactions among immune cells, so as to participate in regulating immune responses. $\mathrm{CD} 8^{+}$inhibitory $\mathrm{T}$ lymphocytes can suppress

TABLE 2: CYTOKINE INDICES ( $X \pm s)$

\begin{tabular}{lccc}
\hline Group & Time & $\mathrm{IL}-6(\mathrm{ng} / \mathrm{l})$ & TNF- $\mathbf{a}(\mathrm{pg} / \mathrm{ml})$ \\
\hline Control group $(\mathrm{n}=48)$ & Before treatment & $89.84 \pm 9.07$ & $391.56 \pm 40.23$ \\
& After treatment & $78.26 \pm 7.93$ & $276.38 \pm 28.45$ \\
Observation group $(\mathrm{n}=39)$ & Before treatment & $90.05 \pm 9.12$ & $387.69 \pm 39.91$ \\
& After treatment & $51.37 \pm 5.29$ & $92.41 \pm 10.07$ \\
$\mathrm{t} / \mathrm{p}_{\text {in the group before treatment }}$ & & $0.107 / 0.915$ & $0.448 / 0.655$ \\
$\mathrm{t} / \mathrm{p}_{\text {in the group after treatment }}$ & & $18.140 / 0.000$ & $38.439 / 0.000$ \\
$\mathrm{t} / \mathrm{p}_{\text {in control group }}$ & & $6.659 / 0.000$ & $16.195 / 0.000$ \\
$\mathrm{t} / \mathrm{p}_{\text {in observation group }}$ & & $22.911 / 0.000$ & $44.800 / 0.000$ \\
\hline
\end{tabular}

TABLE 3: SHORT-TERM THERAPEUTIC EFFECTS (n (\%))

\begin{tabular}{lccccc}
\hline Group & CR & PR & SD & PD & Disease control rate \\
\hline Control group $(\mathrm{n}=48)$ & $0(0.00)$ & $9(18.75)$ & $16(33.33)$ & $23(47.92)$ & $25(52.08)$ \\
Observation group $(\mathrm{n}=39)$ & $4(10.26)$ & $12(30.77)$ & $13(33.33)$ & $10(25.64)$ & $29(74.36)$ \\
$\mathrm{X}^{2}$ & \multicolumn{5}{c}{9.026} \\
$\mathrm{p}$ & \multicolumn{2}{c}{0.029} & & 4.535 \\
\hline
\end{tabular}

TABLE 4: ADVERSE REACTIONS ( $\mathrm{n}(\%)$ )

\begin{tabular}{lccccccc}
\hline Group & $\begin{array}{c}\text { Gastrointestinal } \\
\text { reactions }\end{array}$ & Myelosuppression & $\begin{array}{c}\text { Liver and } \\
\text { kidney damage }\end{array}$ & Fatigue & $\begin{array}{c}\text { Skin } \\
\text { toxicity }\end{array}$ & $\begin{array}{c}\text { Thyroid } \\
\text { toxicity }\end{array}$ & Total \\
\hline $\begin{array}{l}\text { Control group } \\
(\mathrm{n}=48)\end{array}$ & $11(22.92)$ & $7(14.58)$ & $4(8.33)$ & $8(16.67)$ & $0(0.00)$ & $0(0.00)$ & $30(62.50)$ \\
$\begin{array}{l}\text { Observation } \\
\text { group }(\mathrm{n}=39)\end{array}$ & $7(17.95)$ & $4(10.26)$ & $2(5.13)$ & $9(23.08)$ & $4(10.26)$ & $2(5.13)$ & $28(71.79)$ \\
$\mathrm{x}^{2}$ & & & & & & & 0.837 \\
$\mathrm{p}$ & & & & & & & 0.360 \\
\hline
\end{tabular}



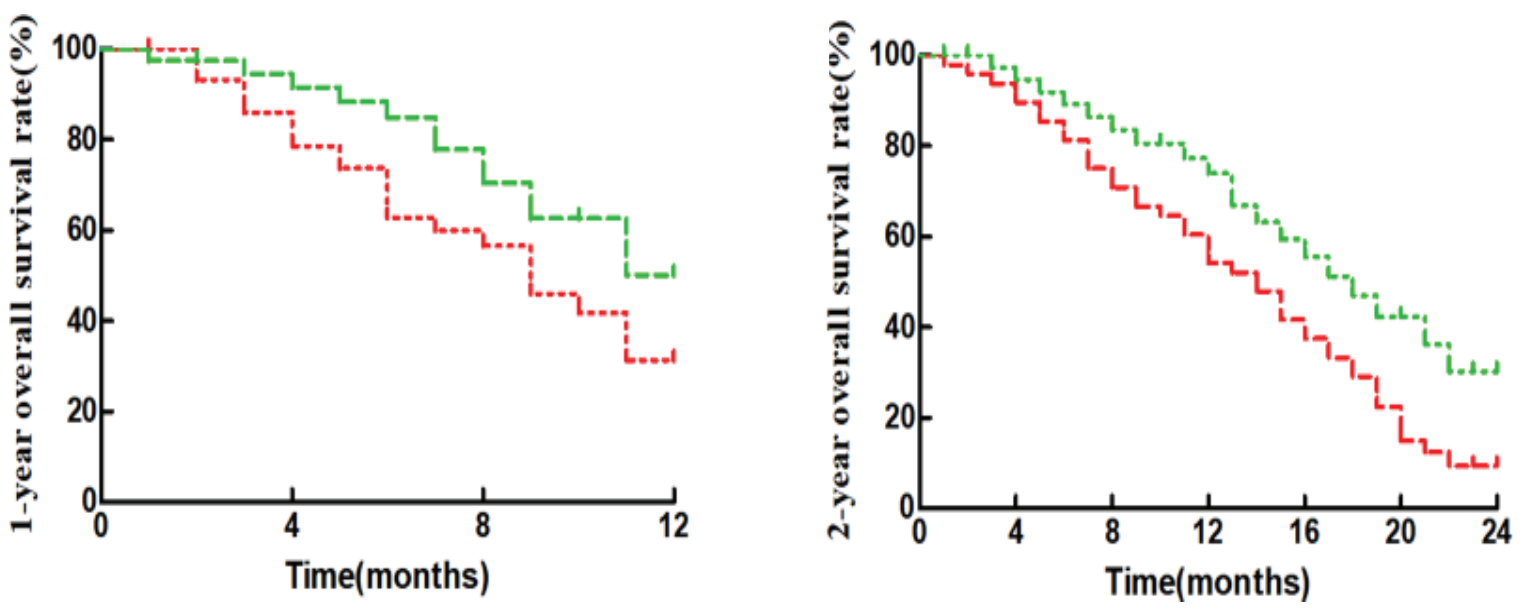

Fig. 1: Survival curves $(-)$ control group, $(-)$ observational group

TABLE 5: INFLUENCING FACTORS FOR SHORT-TERM THERAPEUTIC EFFECTS

\begin{tabular}{lccccc}
\hline Factor & $\mathrm{B}$ & $\mathrm{SE}$ & Wald & $\mathrm{P}$ & OR (95\% Cl) \\
\hline Age & 0.593 & 0.406 & 1.749 & 0.325 & $1.952(0.873 \sim 2.465)$ \\
Gender & 0.685 & 0.574 & 2.136 & 0.678 & $1.234(0.411 \sim 1.637)$ \\
Clinical stage & 0.852 & 0.637 & 2.325 & 0.081 & $2.946(2.163 \sim 3.795)$ \\
$\mathrm{CD}^{+}$ & -0.457 & 0.349 & 2.618 & 0.364 & $0.783(0.246 \sim 1.452)$ \\
$\mathrm{CD}^{+}$ & -0.846 & 0.715 & 2.072 & 0.297 & $1.541(0.985 \sim 2.093)$ \\
$\mathrm{CD}^{+}$ & 0.798 & 0.683 & 1.569 & 0.432 & $1.157(0.628 \sim 1.764)$ \\
$\mathrm{CD}^{+} / \mathrm{CD} 8^{+}$ratio & -1.125 & 0.992 & 2.738 & 0.000 & $0.692(0.214 \sim 0.939)$ \\
IL-6 & 0.571 & 0.468 & 1.294 & 0.516 & $0.839(0.347 \sim 1.582)$ \\
TNF-a & 2.934 & 0.887 & 3.452 & 0.006 & $2.556(1.759 \sim 3.241)$ \\
NF-KB & 0.475 & 0.326 & 1.817 & 0.135 & $1.738(0.259 \sim 2.847)$ \\
Treatment methods & 1.782 & 0.965 & 2.671 & 0.013 & $3.145(1.826 \sim 5.374)$ \\
\hline
\end{tabular}

TABLE 6: INFLUENCING FACTORS FOR LONG-TERM THERAPEUTIC EFFECTS

\begin{tabular}{lccccc}
\hline Factor & $\mathrm{B}$ & $\mathrm{SE}$ & Wald & $\mathrm{P}$ & OR $(95 \% \mathrm{Cl})$ \\
\hline Age & 0.647 & 0.518 & 2.015 & 0.439 & $1.754(0.658 \sim 3.027)$ \\
Gender & 0.791 & 0.623 & 2.487 & 0.154 & $1.468(0.502 \sim 2.169)$ \\
Clinical stage & 1.154 & 0.989 & 3.261 & 0.006 & $3.225(2.136 \sim 4.574)$ \\
$\mathrm{CD}^{+}$ & -0.837 & 0.749 & 2.358 & 0.384 & $0.961(0.449 \sim 1.852)$ \\
$\mathrm{CD}^{+}$ & -0.626 & 0.535 & 3.192 & 0.405 & $1.368(0.873 \sim 2.416)$ \\
$\mathrm{CD}^{+}$ & 0.739 & 0.627 & 1.463 & 0.136 & $1.557(0.759 \sim 1.861)$ \\
$\mathrm{CD}^{+} / \mathrm{CD} 8^{+}$ratio & -1.145 & 0.892 & 1.738 & 0.001 & $0.783(0.328 \sim 0.925)$ \\
IL-6 & 2.834 & 0.687 & 6.459 & 0.247 & $2.015(0.869 \sim 3.443)$ \\
TNF-a & 1.053 & 0.934 & 4.725 & 0.003 & $2.348(1.673 \sim 3.759)$ \\
NF-KB & 0.593 & 0.458 & 1.304 & 0.210 & $0.895(0.427 \sim 1.956)$ \\
Treatment methods & 1.379 & 0.892 & 2.248 & 0.009 & $3.426(2.015 \sim 4.893)$ \\
\hline
\end{tabular}

immune responses and further help tumor cells to evade the immune attack in organisms, thus promoting the development and progression of tumors. The low $\mathrm{CD}^{+}$/ $\mathrm{CD}^{+}$ratio, an evaluation index for immune disorders in the body, suggests cellular immunosuppression. According to the results of this study, pembrolizumab, a PD-1 inhibitor, helps to make the disordered $\mathrm{T}$ lymphocyte subpopulations closer to balance faster and restore their functions in patients with advanced nonsquamous non-small cell lung cancer. These results are consistent with the effects of pembrolizumab on the $\mathrm{T}$ lymphocytes in advanced non-small lung cancer reported previously ${ }^{[5]}$.

Under normal conditions, TNF- $\alpha$ produced by mononuclear phagocytes has beneficial effects on 
organisms, such as anti-infection and anti-tumor effects. However, pathologically, large quantities of TNF- $\alpha$ cannot only directly damage cells, but also stimulate immune cells to generate pro-inflammatory mediators such as IL-1, IL-6 and IL-8, so as to enhance inflammatory cascades. Thus, TNF- $\alpha$ is involved in the inflammation and shock reactions, and promotes the growth, proliferation, invasion, metastasis and angiogenesis of tumor cells ${ }^{[6]}$. It has long been confirmed that IL- 6 can accelerate the progression of inflammation, induce the growth and differentiation of tumor cells, but inhibit their apoptosis. Besides, it is able to promote tumor angiogenesis, but repress the anti-tumor immune function in organisms ${ }^{[7]}$. The levels of TNF- $\alpha$ and IL-6 obviously rise in the serum of patients with lung cancer ${ }^{[8]}$. In the present study, the patients with advanced non-squamous non-small cell lung cancer had higher levels of TNF- $\alpha$ and IL- 6 in the serum before treatment, corresponding with the early study reports. The levels of TNF- $\alpha$ and IL- 6 declined after treatment, and the decreases were greater in the patients administered with the PD-1 inhibitor pembrolizumab. The reason may be that the proliferation, differentiation and other biological behaviors of tumor cells are repressed due to the attack and killing by immune cells after the removal of immunosuppression in patients, so that their secreted toxic metabolites are decreased to a large extent, thereby alleviating the activation of mononuclear phagocytes and obviously lowering the levels of TNF- $\alpha$ and IL6. Moreover, a low level of TNF- $\alpha$ is likely to resist tumors and inhibit the secretion of IL-6. Different from the above reason, it was inferred in the study of Zheng et al. ${ }^{[9]}$ that the decrease in TNF- $\alpha$ and IL-6 levels may be closely associated with the different treatment cycles and detection time. In this study, the treatment cycle was longer and the immune function of the body had been restored to the best state in the time of detection, while the decreases were probably caused by the stress response of the body to the treatment after 2 cycles in the study of Zheng et al. ${ }^{[9]}$.

Pembrolizumab, as a second-line therapy regimen, has long been corroborated to have significant efficacy and favorable safety and tolerability for non-small cell lung cancer ${ }^{[10]}$. A recent study demonstrated that pembrolizumab combined with platinumbased chemotherapeutics, as the first-line treatment scheme of advanced non-small lung cancer, is more efficacious than pembrolizumab or platinum-based chemotherapeutics, and it prolongs the survival time of patients and raises the survival rate, without increasing the incidence rate of severe adverse reactions ${ }^{[11]}$. The above conclusions support the results of the short-term efficacy, adverse reactions and long-term prognosis in this study. According to the logistic multivariable regression analysis results, a lower $\mathrm{CD} 4^{+} / \mathrm{CD} 8^{+}$ratio, a higher TNF- $\alpha$ level and chemotherapy were the risk factors for the poor short-term efficacy and long-term prognosis in patients with advanced non-squamous nonsmall cell lung cancer $(\mathrm{p}<0.05)$, and the clinical stage IV was also a risk factor for the unfavorable long-term prognosis of patients $(\mathrm{p}<0.05)$. A lower $\mathrm{CD}^{+} / \mathrm{CD}^{+}$ ratio indicates cellular immunosuppression, and the immunosuppression in patients cannot be eliminated by chemotherapy, so that immune cells fail to exert an anti-tumor effect. Previously, some scholars reported that TNF- $\alpha$ can serve as an important marker for the poor chemotherapy response and prognosis ${ }^{[12]}$. Clinical stage is a vital basis for the judgment of non-small cell lung cancer conditions and the selection of treatment regimens, and numerous clinical data have shown that a later clinical stage is more harmful for surgical treatment, shortening the survival time and lowering the survival rate of patients ${ }^{[13]}$.

In summary, pembrolizumab combined with paclitaxel and cisplatin chemotherapy regimen can relieve the cellular immunosuppression and alleviate inflammatory response to improve the short-term efficacy and longterm prognosis, without raising the incidence rate of severe adverse reactions in the treatment of advanced non-squamous non-small cell lung cancer, thereby providing new guidance for the selection of treatment schemes for advanced non-squamous non-small cell lung cancer. In the future, the sample size will be further enlarged, and the optimal use time and dose of pembrolizumab and chemotherapy drugs will be also delved into and aiming to lay a foundation for formulating the individualized treatment regimens.

\section{Acknowledgements:}

None

\section{Conflict of interests:}

The authors declared no conflict of interest.

\section{REFERENCES}

1. Zheng Y, Li Y, Liu X, Zhang R, Wang Z, Sun H, et al. A phase III, multicenter randomized controlled trial of neo-adjuvant chemotherapy paclitaxel plus cisplatin versus surgery alone for stage IIA-IIIB esophageal squamous cell carcinoma. J Thorac Dis 2017;9(1):200-4.

2. Toulmonde M, Penel N, Adam J, Chevreau C, Blay JY, Le Cesne A, et al. Use of PD-1 targeting, macrophage infiltration, and IDO pathway activation in sarcomas: a phase 2 clinical 
trial. JAMA Oncol 2018;4(1):93-7.

3. Yuan X, Qu P, Fang J, Cai S, Fu S. Effect of Epidural Anesthesia on the Immune Function of Patients with Non-small Cell Lung Cancer. Int J Pharmacol 2018;14(6):826-34.

4. Saruwatari K, Sato R, Nakane S, Sakata S, Takamatsu K, Jodai $\mathrm{T}$, et al. The risks and benefits of immune checkpoint blockade in anti-AChR antibody-seropositive non-small cell lung cancer patients. Cancers 2019;11(2):140.

5. Sugisaka J, Sugawara S, Toi Y, Ogasawara T, Aso M, Tsurumi K, et al. Pembrolizumab plus chemotherapy versus pembrolizumab monotherapy for PD-L1-positive advanced non-small cell lung cancer in the real world. Ann Oncol 2019;30:ix112-3.

6. Huang J, Ning N, Zhang W. Effects of paraquat on IL-6 and TNF- $\alpha$ in macrophages. Exp Ther Med 2019;17(3):1783-9.

7. Tutkun L, Iritas SB, Deniz S, Oztan O, Abusoglu S, Unlu A, et $a l$. TNF- $\alpha$ and IL- 6 as biomarkers of impaired lung functions in dimethylacetamide exposure. J Med Biochem 2019;38(3):27683.

8. Shang GS, Liu L, Qin YW. IL-6 and TNF- $\alpha$ promote metastasis of lung cancer by inducing epithelial-mesenchymal transition.
Oncol Lett 2017;13(6):4657-60.

9. Zheng $\mathrm{X}, \mathrm{Hu}$ Y. Correlation between therapeutic effects and changes in serum TNF- $\alpha$ levels in patients with advanced nonsmall cell lung cancer before and after anti-PD-1 treatment. Acad J Chin PLA Med Sch 2019;40(3):231-4.

10. Carbone DP, Reck M, Paz-Ares L, Creelan B, Horn L, Steins $\mathrm{M}$, et al. First-line nivolumab in stage IV or recurrent nonsmall-cell lung cancer. N Engl J Med 2017;376(25):2415-26.

11. Shukla NA, Yan MN, Hanna N. The Story of Angiogenesis Inhibitors in Non-small-cell Lung Cancer: The Past, Present, and Future. Clin Lung Cancer 2020;21(4):308-13.

12. Tanaka R, Okiyama N, Okune M, Ishitsuka Y, Watanabe R, Furuta $\mathrm{J}$ et al. Serum level of interleukin-6 is increased in nivolumab-associated psoriasiform dermatitis and tumor necrosis factor- $\alpha$ is a biomarker of nivolumab recativity. J Dermatol Sci 2017;86(1):71-3.

13. Yildirim F, Turk M, Yurdakul AS, Ozturk C. Prognosis of advanced stage non-small cell lung cancer: Is it different in patients with chronic obstructive pulmonary disease? Int J Clin Exp Med 2018;11(9):9603-11. 